\title{
Condicionamento osmótico de sementes de hortaliças visando a germi- nação em condições de temperaturas baixas
}

\author{
Warley Marcos Nascimento \\ Embrapa Hortaliças, C. Postal 218, 70359-970 Brasília-DF; E-mail:wmn@cnph.embrapa.br
}

\section{RESUMO}

Baixas temperaturas por ocasião do plantio podem atrasar ou inibir a germinação das sementes de várias espécies de hortaliças, incluindo berinjela, melancia, melão e tomate. O condicionamento osmótico de sementes tem sido utilizado com o objetivo de acelerar a germinação e uniformizar a emergência das plântulas em campo, especialmente em condições adversas. Sementes de berinjela 'Ciça', melancia 'Crimson Sweet', melão 'Top Net SR' e tomate 'Heinz 9425 ' foram osmoticamente condicionadas. A metodologia utilizada no condicionamento osmótico foi dependente da espécie, isto é, a solução osmótica, a temperatura bem como o período de condicionamento variou entre as diferentes espécies estudadas. Após o condicionamento osmótico, as sementes foram lavadas e secas. As sementes foram colocadas para germinar em condições de baixas temperaturas $\left(10 ; 15 ; 15\right.$ e $17^{\circ} \mathrm{C}$ para tomate, berinjela, melancia e melão, respectivamente) e em temperaturas normais $\left(20\right.$ e $30^{\circ} \mathrm{C}$ para tomate e $25^{\circ} \mathrm{C}$ para as demais espécies). Baixas temperaturas diminuíram a velocidade e a percentagem de germinação das sementes das quatro espécies. Sementes osmoticamente condicionadas de todas as espécies testadas apresentaram maior germinação do que aquelas não condicionadas, principalmente em condições de baixas temperaturas. O condicionamento osmótico pode ser utilizado para melhorar a germinação de sementes de cucurbitaceas (melão e melancia) e solanaceas (berinjela e tomate), principalmente nestas condições adversas de baixas temperaturas.

Palavras-chave: Citrullus lanatus, Cucumis melo, Lycopersicon esculentum, Solanum melongena, estabelecimento de plântulas, termo-inibição.

\section{ABSTRACT \\ Vegetable seed priming to improve germination at low temperature}

Under low temperatures, seed germination of several species, including eggplant, watermelon, melon and tomato can be erratic or completely inhibited. Seed priming has been used to increase germination rate and seedling uniformity, mainly under unfavorable environmental conditions. Seeds of eggplant, cv. 'Ciça', watermelon 'Crimson Sweet', melon 'Top Net SR' and tomato 'Heinz 9425' were osmoconditioned. The methodology for seed priming was speciesdependent. The osmotic solution, temperature as well as conditioning period varied among the species. After seed conditioning, seeds were washed and dried. Seeds were incubated in a germination chamber at low $\left(10 ; 15 ; 15\right.$ and $17^{\circ} \mathrm{C}$ for tomato, eggplant, watermelon and melon, respectively) and normal temperatures $\left(20\right.$ and $30^{\circ} \mathrm{C}$ for tomato and $25^{\circ} \mathrm{C}$ for the other species). Low temperatures decreased germination percentage and germination rate. Primed seeds from all species had higher germination compared to unprimed seeds, especially in low temperatures. Priming may be used to improve germination performance of cucurbitaceous (watermelon and melon) and solancaeous (tomato and eggplant) seeds especially under low temperature.

Keywords: Citrullus lanatus, Cucumis melo, Lycopersicon esculentum, Solanum melongena, seedling establishment, thermoinhibition.

(Recebido para publicação em 8 de fevereiro de 2004 e aceito em 7 de abril de 2005)

$\mathrm{O}_{\mathrm{p}=1}$ sucesso da produção olerícola dependerá, dentre outros aspectos, de aceitável estabelecimento de plântulas no campo, fator este diretamente relacionado com a germinação das sementes. O período compreendido entre a semeadura e o estabelecimento das plântulas é fase crucial da produção olerícola. Assim, sementes de alta qualidade e condições que permitam máxima germinação em menor tempo possível, com máxima uniformidade de plântulas, é, sem dúvida alguma, busca constante daqueles envolvidos na cadeia produtiva de hortaliças.

Utilizando sementes com alta germinação e vigor, os produtores terão maior probabilidade de êxito na forma- ção da lavoura. A utilização de sementes de alta qualidade fisiológica irá minimizar o risco com perdas durante o estabelecimento de plântulas, seja na estufa (transplante) ou no campo (semeadura direta). Isto torna-se bastante importante neste segmento, visto que em grande número de espécies olerícolas, cada semente irá produzir um único produto comercial. Soma-se a isto, o alto custo das sementes das novas cultivares ou híbridos de hortaliças atualmente existentes no mercado.

Diversos fatores poderão afetar a germinação e consequentemente a emergência das plântulas. Dentre os fatores, a temperatura poderá vir a ser o mais importante, uma vez que nem sempre o produtor tem o total controle sobre este fator. Cada espécie apresenta temperatura mínima, máxima, e ótima para a germinação, e dentro desta, podem existir diferenças marcantes entre as cultivares quanto à germinação (NASCIMENTO, 2000). Temperaturas muito baixas ou muito altas poderão alterar tanto a velocidade quanto a porcentagem final de germinação. Geralmente, temperaturas baixas reduzem a velocidade de germinação, enquanto temperaturas altas aumentam.

Condições de baixas temperaturas, próximas de $15^{\circ} \mathrm{C}$, reduzem a velocidade de germinação das sementes e a emergência de plântulas de várias espécies, incluindo aquelas das famílias das cu- 
curbitáceas, tais como abóbora, melão, melancia, pepino, entre outras ou das solanáceas como berinjela, pimentão e tomate. Além disso, a incidência de alguns microrganismos do solo causadores de tombamento é favorecida pelas condições de baixas temperaturas, havendo assim uma redução do estande com conseqüências negativas na produtividade.

Visando uma melhoria na qualidade das sementes e rápido e uniforme estabelecimento de plântulas no campo e/ou na estufa, diferentes tipos de tratamentos têm sido estudados, dentre eles, o condicionamento osmótico, que consiste de hidratação controlada das sementes, suficiente para promover atividades pré-metabólicas, sem, contudo, permitir a emissão da raiz primária (HEYDECKER et al., 1973). Em geral, o tratamento consiste em embeber as sementes em uma solução osmótica por determinado período e após isso, secar as sementes para o grau de umidade original (NASCIMENTO, 1998), o que possibilita a vantagem de se poder manuseá-las e/ou armazená-las. $\mathrm{O}$ condicionamento osmótico tem sido utilizado principalmente em sementes de hortaliças, com o objetivo de melhorar a germinação, a uniformidade das plântulas e algumas vezes a porcentagem de germinação, especialmente em condições edafo-climáticas adversas (BRADFORD, 1986; KHAN, 1992; PARERA; CANTLIFFE, 1994, NASCIMENTO, 1998).

Os efeitos do condicionamento osmótico no maior desempenho da germinação de sementes e emergência das plântulas sob condições de baixas temperaturas foram relatados em várias hortaliças, incluindo berinjela (TRIGO; TRIGO, 1999), brássicas (RAO et al., 1987; ZHENG et al., 1994), cenoura (SZAFIROWSKA et al., 1981; SAMPAIO; SAMPAIO, 1998), melancia (SACHS, 1977), melão (BRADFORD, 1985; NERSON; GOVERS, 1986; BRADFORD et al., 1988; PASSAM et al., 1989; WELBAUM; BRADFORD, 1991; DHILLON, 1995; OLUOCH; WELBAUM, 1996; YEOUNG et al., 1996; NASCIMENTO, 2002), milhodoce (BENNETT; WATERS JR., 1987; MURRAY, 1990), pimentão (ROVERI JOSÉ, 1999), salsa (AKERS et al., 1987) e tomate (ALI et al., 1990), dentre outras.

Esta melhoria do condicionamento osmótico pode estar intimamente rela- cionada com o mecanismo de reparo das membranas celulares que ocorrem durante o condicionamento osmótico (BURGASS; POWELL, 1984), uma vez que as sementes durante o processo de maturação e/ou durante o armazenamento, deterioram-se e necessitam de um reparo durante a embebição para germinarem satisfatoriamente (OSBORNE, 1983); no condicionamento osmótico esta embebição é mais lenta. Soma-se a isto, que as sementes foram condicionadas sob condições de temperaturas mais altas, isto é, variando de 20 a $25^{\circ} \mathrm{C}$. O condicionamento osmótico estende a "lag phase" (fase II) da embebição de água, restringindo a emissão da radícula, e nesta fase ocorrem os maiores eventos metabólicos preparando as sementes para a fase III com a protrusão da radícula (BEWLEY; BLACK, 1994). Assim, um período prolongado na fase II que ocorre durante o condicionamento osmótico, pode promover algum mecanismo específico necessário à germinação em condições de temperaturas adversas (NASCIMENTO et al., 2003), incluindo baixas temperaturas. Em adição, o comprimento da fase II é dependente em temperatura; a embebição das sementes a 20 ou $25^{\circ} \mathrm{C}$ durante o condicionamento osmótico procede em níveis adequados para contornar a termo-inibição causada por baixas temperaturas.

Diante do exposto, o objetivo desse estudo foi verificar o efeito do condicionamento osmótico na germinação de sementes de berinjela, melancia, melão e tomate sob condições de baixas temperaturas.

\section{MATERIAL E MÉTODOS}

Os experimentos foram conduzidos em laboratório da Embrapa Hortaliças, Brasília, DF, de maio a outubro de 1999 (melão e tomate), fevereiro a abril de 2000 (melancia), e março a maio de 2001 (berinjela). Foram conduzidos quatro ensaios em laboratório para avaliar o efeito do condicionamento osmótico de sementes em condições de baixas temperaturas. Em cada ensaio, estudou-se uma espécie. O delineamento experimental, para os quatro experimentos, foi inteiramente ao acaso com quatro repetições.
Berinjela: Foram utilizadas sementes híbridas da cultivar Ciça (Embrapa Hortaliças), as quais foram submetidas ao condicionamento osmótico. Para tanto, dez gramas de sementes foram condicionadas em Erlenmeyers contendo $250 \mathrm{ml}$ de solução aerada de nitrato de potássio $\left(\mathrm{KNO}_{3}\right)$ a $0,35 \mathrm{M}$ por 24 horas de embebição, a $20^{\circ} \mathrm{C}$ sob luz. A aeração foi provida por uma bomba de aquário. Após a embebição, as sementes foram lavadas em água corrente, e secas a temperatura ambiente por dois dias, e após, a $38^{\circ} \mathrm{C}$ por 24 horas. Quatro repetições de 50 sementes foram semeadas sobre duas folhas de papel de germinação, em caixas gerbox, umedecidas com água destilada, e incubadas em germinadores a 15 e $25^{\circ} \mathrm{C}$, sob luz. Foram realizadas contagens (computadas aquelas sementes germinadas, isto é, com emissão da radícula) aos sete e 14 dias.

Melancia: Foram utilizadas sementes da cv. Crimson Sweet (Horticeres), as quais foram osmoticamente condicionadas por 96 horas, a $20^{\circ} \mathrm{C}$, sob luz, em solução aerada de $\mathrm{KNO}_{3}(0,35 \mathrm{M})$. A aeração e demais métodos utilizados foi conforme descrita para as sementes de berinjela, com exceção do tempo para embebição que foi de 96 horas. Após a embebição, as sementes também foram lavadas em água corrente e colocadas para secar à temperatura de $15^{\circ} \mathrm{C} \mathrm{du}$ rante dois dias. Porcentagem e velocidade de germinação foram avaliadas a 15 e $25^{\circ} \mathrm{C}$. Sementes germinadas foram contadas diariamente, sendo a velocidade de germinação calculada de acordo com a fórmula $\mathrm{S} \mathrm{Ti} \mathrm{Ni} / \mathrm{S} \mathrm{Ni}$, onde Ni é o número de sementes germinadas a cada dia no dia Ti (MAGUIRE, 1962).

Melão: Foram utilizadas sementes da cv. Top Net SR (Harris Moran) as quais foram condicionadas em solução aerada de $\mathrm{KNO}_{3}(0,35 \mathrm{M})$, durante seis dias, a $25^{\circ} \mathrm{C}$, no escuro. A aeração e demais métodos utilizados foi conforme descrita anteriormente. Após isto, as sementes foram lavadas em água corrente por dois minutos, e colocadas para secar a temperatura de $15^{\circ} \mathrm{C}$ durante dois dias. As sementes foram colocadas para germinar a 17 e $25^{\circ} \mathrm{C}$.

Tomate: Sementes da cultivar Heinz 9425 (H.J. Heinz) foram osmoticamente condicionadas em solução aerada de 
$\mathrm{KNO}_{3}(0,30 \mathrm{M})$ durante sete dias a $20^{\circ} \mathrm{C}$, sob constante luz. A aeração e demais métodos utilizados foi conforme descrita anteriormente. Após isto, as sementes foram lavadas em água corrente por dois minutos, e colocadas para secar a temperatura de $15^{\circ} \mathrm{C}$ durante dois dias. As sementes foram colocadas para germinar a $10 ; 20$ e $30^{\circ} \mathrm{C}$.

\section{RESULTADOS E DISCUSSÃO}

Berinjela: A temperatura ideal para a germinação dessa espécie é em torno de 20 a $30^{\circ} \mathrm{C}$, segundo as Regras para Análise de Sementes (BRASIL, 1992). O condicionamento osmótico aumentou a velocidade de germinação das sementes em condições normais $\left(25^{\circ} \mathrm{C}\right)$ (Tabela 1). As sementes osmoticamente condicionadas germinaram totalmente (95\%) aos sete dias. A germinação aos 14 dias, foi semelhante, sendo que sementes condicionadas proporcionaram melhor performance a $25^{\circ} \mathrm{C}$. Baixas temperaturas $\left(15^{\circ} \mathrm{C}\right)$ entretanto, reduziram a germinação das sementes, sendo que sementes não condicionadas germinaram apenas $22 \%$, enquanto aquelas condicionadas germinaram 94\% (Tabela 1). Resultados semelhantes também foram obtidos em berinjela por Trigo e Trigo (1999).

Melancia: Baixa temperatura $\left(15^{\circ} \mathrm{C}\right)$ reduziu a velocidade e a porcentagem de germinação das sementes (Tabela 2). As sementes osmoticamente condicionadas germinaram mais rápido do que aquelas não condicionadas, principalmente em condições de baixas temperaturas. Não foi observada diferença significativa entre a percentagem de germinação das sementes condicionadas e não condicionadas nas duas temperaturas avaliadas.

Melão: Foi observado que a $17^{\circ} \mathrm{C}$ as sementes osmoticamente condicionadas apresentaram maior e mais rápida germinação, confirmando que o condicionamento osmótico, em melão, pode ser altamente benéfico, principalmente nas condições adversas de germinação a baixas temperaturas. Já em condições ótimas $\left(25^{\circ} \mathrm{C}\right)$, a porcentagem de germinação das sementes condicionadas e não condicionadas não diferiu estatisticamente (Tabela 3).

Tabela 1. Germinação aos 7 e 14 dias de sementes de berinjela 'Ciça' condicionadas e não condicionadas, incubadas a 15 e $25^{\circ} \mathrm{C}$, sob luz. Brasília, Embrapa Hortaliças, 2001.

\begin{tabular}{lccccc}
\hline \multirow{2}{*}{ Tratamento } & \multicolumn{4}{c}{ Germinação (\%) } \\
\cline { 2 - 4 } & \multicolumn{3}{c}{$\mathbf{7}$ dias } & & $\mathbf{1 4}$ dias \\
\cline { 2 - 3 } \cline { 5 - 6 } & $\mathbf{1 5 ^ { \circ } \mathbf { C }}$ & $\mathbf{2 5 ^ { \circ } \mathbf { C }}$ & & $\mathbf{1 5 ^ { \circ } \mathbf { C }}$ & $\mathbf{2 5 ^ { \circ } \mathbf { C }}$ \\
\hline Condicionadas & $0 \mathrm{a}^{1}$ & $95 \mathrm{a}$ & & $94 \mathrm{a}$ & $95 \mathrm{a}$ \\
Não condicionadas & $0 \mathrm{a}$ & $75 \mathrm{~b}$ & & $22 \mathrm{~b}$ & $86 \mathrm{~b}$ \\
\hline
\end{tabular}

${ }^{1}$ Médias na vertical, seguidas pela mesma letra nas colunas, não diferem entre si, pelo teste de Duncan, a 5\% de probabilidade.

Tabela 2. Velocidade de germinação (horas) e germinação (\%) de sementes osmoticamente condicionadas e não condicionadas de melancia 'Crimson Sweet', incubadas a 15 e $25^{\circ} \mathrm{C}$, sob luz. Brasília, Embrapa Hortaliças, 2000.

\begin{tabular}{|c|c|c|c|c|}
\hline \multirow{2}{*}{ Tratamento } & \multicolumn{2}{|c|}{ Veloc. germ. (horas) } & \multicolumn{2}{|c|}{ Germinação (\%) } \\
\hline & $15^{\circ} \mathrm{C}$ & $25^{\circ} \mathrm{C}$ & $15^{\circ} \mathrm{C}$ & $25^{\circ} \mathrm{C}$ \\
\hline Condicionadas & $144.0 b^{1}$ & $40.8 \mathrm{a}$ & $59 a$ & $95 \mathrm{a}$ \\
\hline Não condicionadas & 210.6 a & $55.2 \mathrm{a}$ & 56 a & $93 \mathrm{a}$ \\
\hline
\end{tabular}

${ }^{1}$ Médias seguidas pela mesma letra nas colunas, não diferem entre si, pelo teste de Duncan, a $5 \%$ de probabilidade.

Tabela 3. Velocidade de germinação (horas) e germinação (\%) de sementes osmoticamente condicionadas e não condicionadas de melão 'Top Net SR', incubadas a 17 e $25^{\circ} \mathrm{C}$, sob luz. Brasília, Embrapa Hortaliças, 1999.

\begin{tabular}{lccccc}
\hline \multirow{2}{*}{ Tratamento } & \multicolumn{2}{c}{ Veloc. germ. (horas) } & & \multicolumn{2}{c}{ Germinação (\%) } \\
\cline { 2 - 3 } \cline { 5 - 6 } & $\mathbf{1 7 ^ { \circ } \mathrm { C }}$ & $\mathbf{2 5 ^ { \circ } \mathrm { C }}$ & & $\mathbf{1 7 ^ { \circ } \mathrm { C }}$ & $\mathbf{2 5 ^ { \circ } \mathbf { C }}$ \\
\hline Condicionadas & $98.4 \mathrm{~b}^{1}$ & $38.6 \mathrm{a}$ & & $87 \mathrm{a}$ & $89 \mathrm{a}$ \\
Não condicionadas & $158.5 \mathrm{a}$ & $54.5 \mathrm{a}$ & & $72 \mathrm{~b}$ & $91 \mathrm{a}$ \\
\hline
\end{tabular}

${ }^{1}$ Médias seguidas pela mesma letra nas colunas, não diferem entre si, pelo teste de Duncan, a $5 \%$ de probabilidade.

Tabela 4. Velocidade de germinação (horas) e germinação (\%) de sementes osmoticamente condicionadas e não condicionadas de tomate 'Heinz 9425 ', incubadas a 10,20 e $30^{\circ} \mathrm{C}$, sob luz. Brasília, Embrapa Hortaliças, 1999.

\begin{tabular}{|c|c|c|c|c|c|c|}
\hline \multirow[t]{2}{*}{ Tratamento } & \multicolumn{3}{|c|}{$\begin{array}{l}\text { Velocidade germinação } \\
\text { (horas) }\end{array}$} & \multicolumn{3}{|c|}{ Germinação (\%) } \\
\hline & $10^{\circ} \mathrm{C}$ & $20^{\circ} \mathrm{C}$ & $30^{\circ} \mathrm{C}$ & $10^{\circ} \mathrm{C}$ & $20^{\circ} \mathrm{C}$ & $30^{\circ} \mathrm{C}$ \\
\hline Condicionadas & $113.6 b^{1}$ & $47.8 \mathrm{a}$ & $31.6 \mathrm{a}$ & $93 a$ & $93 a$ & $96 a$ \\
\hline Não condicionadas & $184.5 \mathrm{a}$ & $55.3 a$ & $48.3 \mathrm{a}$ & $95 \mathrm{a}$ & 95 a & $99 \mathrm{a}$ \\
\hline
\end{tabular}

${ }^{1}$ Médias seguidas pela mesma letra nas colunas, não diferem entre si, pelo teste de Duncan, a $5 \%$ de probabilidade.

Tomate: Baixas temperaturas $\left(10^{\circ} \mathrm{C}\right)$ diminuíram a velocidade e a percentagem de germinação das sementes (Tabela 4). Quanto maior a temperatura, mais rápida foi a germinação. Sementes osmoticamente condicionadas além de germinarem mais rapidamente, apresentaram uma maior percentagem de germinação (93\%) do que aquelas não tratadas (46\%), principalmente em condições de baixas temperaturas. Nas temperaturas de 20 e $30^{\circ} \mathrm{C}$ não foram ob- servadas diferenças significativas na velocidade e na porcentagem de germinação entre as sementes condicionadas e não condicionadas. Isto mais uma vez, evidencia que os maiores benefícios do condicionamento osmótico ocorrem sob condições adversas.

Como esperado, a velocidade de germinação das sementes dessas quatro espécies diminuiu quando incubadas em condições de baixas temperaturas, e o condicionamento osmótico aumentou 
esta velocidade de germinação. O rápido estabelecimento da cultura no campo poderá ainda implicar em menor risco, uma vez que a germinação das sementes e a emergência das plântulas podem ser marcadamente reduzidas pela ação de microrganismos, especialmente de fungos dos gêneros Pythium, Phytophthora, Rhizoctonia e Fusarium (Agrios, 1988). Em beterraba, têm-se utilizado sementes condicionadas para minimizar o efeito desses microrganismos, reduzindo assim a incidência de dampingoff (TAYLOR et al.,1985; OSBURN; SCHROTH, 1989; RUSH, 1991).

A germinação também pode ser reduzida sob condições de baixas temperaturas, como foi observado neste estudo. Isto pode ter havido efeito temporário de termo-inibição, uma vez que as sementes poderão germinar, caso a temperatura atinja valores adequados para a germinação da espécie em questão. Em alface, este fenômeno também tem sido observado, embora em condições de altas temperaturas, isto é, $35^{\circ} \mathrm{C}$ (NASCIMENTO; CANTLIFFE, 2002). Em outros casos, quando ocorrem temperaturas muito baixas (próximas de $5^{\circ} \mathrm{C}$ ) por ocasião da embebição, pode haver injúria de frio (chilling injury) (HERNER, 1986). Isto ocorre, principalmente em sementes de feijão-vagem, grão-de-bico, ervilha e milho-doce, em virtude da rápida embebição das sementes, geralmente muito secas, sob baixas temperaturas (HERNER, 1986); nestas condições, as sementes sofrem uma maior exsudação dos componentes celulares.

De acordo com os resultados, temse que baixas temperaturas representam uma limitação no estabelecimento de berinjela, tomate, melão e melancia, e o condicionamento osmótico de sementes pode ser utilizado nessas espécies para melhorar a performance da germinação e estabelecimento de plântulas em condições de baixas temperaturas.

\section{LITERATURA CITADA}

AGRIOS, G.N. Plant Pathology. 3 ed. Academic Press. San Diego, 1988. 803 p.

AKERS, S.W; BERKOWITZ, G.A.; RABIN, J. Germination of parsley seed primed in aerated solutions of polyethylene glycol. HortScience, v.22, n.2, p.250-252, 1987.
ALI, A.V.; SOUZA MACHADO, V.; HAMILL, A.S. Osmoconditioning of tomato and onion seeds. Scientia Horliculturae, v.43, p.213-224, 1990.

BENNETT, M.A.; WATERS JR., L. Seed hydration treatments for improved sweet corn germination and stand establishment. Journal of the American Society for Horticultural Science, v.112, n.1, p.45-49, 1987.

BEWLEY, J.D.; BLACK, M. Seeds: Physiology of development and germination. 2. ed. New York: Plenum Press, 1994. 445 p.

BRADFORD, K.J. Seed priming improves germination and emergence of cantaloupe at low temperature. HortScience, v.20, p.598, 1985.

BRADFORD, K.J. Manipulation of seed water relations via osmotic priming to improve germination under stress conditions. HortScience, v.21, n.5, p.1105-1112, 1986.

BRADFORD, K.J.; MAY, D.M.; HOYLE, B.J.; SHIBINSKI, Z.S.; SCOTT, S.J.; TYLER, K.B. Seed and soil treatments to improve emergence of muskmelon from cold or crusted soils. Crop Science, v.28, p.1001-1005, 1988.

BRASIL. Ministério da Agricultura e da Reforma Agrária. Regras para análise de sementes. Brasília: SNDA/DNDV/CLAV, 1992, 365 p.

BURGASS, R.W.; POWELL, A.A. Evidence for repair processes in the invigoration of seeds by hydration. Annals of Botany, v.53, p.753-757, 1984. DHILLON, N.P.S. Seed priming of male sterile muskmelon (Cucumis melo L.) for low temperature germination. Seed Science and Technology, v.23, p.881-884, 1995.

HERNER, R.C. Germination under cold soil conditions. HortScience, v.21, n.5, p.1118-1122, 1986.

HEYDECKER, W.; HIGGIS, J.; GULLIVER, R.L. Accelerated germination by osmotic treatment. Nature, v.246, p.42-44, 1973.

KHAN, A.A. Preplant physiological seed conditioning. Horticultural Reviews, v.13, p.131181, 1992

MAGUIRE, J.D. Seeds of germination-aid in selection and evaluation for seeding emergence and vigor. Crop Science, v.2, p.176-177, 1962.

MURRAY, G.A. Priming sweet corn seed to improve emergence under cool conditions. HortScience, v.25, n.2, p.231, 1990.

NASCIMENTO, W.M. Condicionamento osmótico de sementes de hortaliças: potencialidades e implicações. Horticultura Brasileira, Brasília, v.16, n.2, p.106-109, 1998.

NASCIMENTO, W.M. Temperatura x germinação. Seednews, v.4, n.4, p.44-45, 2000.

NASCIMENTO, W.M. Sementes de melão osmoticamente condicionadas: vale a pena utilizálas? Horticultura Brasileira, Brasília, v.20, n.2, p.133-135, 2002.

NASCIMENTO, W.M. Preventing thermoinhibition in a thermo-sensitive lettuce genotype by seed imbibition at low temperature. Scientia Agricola, v.60. n.3, p.477-480, 2003.

NASCIMENTO, W.M; CANTLIFFE, D.J. Germinação de sementes de alface sob altas temperaturas. Horticultura Brasileira, Brasília, v.20, n.1, p.103-106, 2002.

NERSON, H.; GOVERS, A. Salt priming of muskmelon seeds for low-temperature germination. Scientia Horticulturae, v.2, p.85-91, 1986.
OLUOCH, M.O.; WELBAUM, G.E. Effect of postharvest washing and post-storage priming on viability and vigour of six-year-old muskmelon (Cucumis melo L.) seeds from eight stages of development. Seed Science and Technology, v.24, p.195-209, 1996.

OSBORNE, D.J. Biochemical control of systems operating in the early hours of germination. Canadian Journal of Botany, v.61, p.3568-3577, 1983.

OSBURN, R.M.; SCHROTH, M.N. Effect of osmopriming sugar beet seed on germination rate and incidence of Pythium ultimum damping-off. Plant Disease, v.73, p.21-24, 1989.

PARERA, C.A.; CANTLIFFE, D.J. Presowing seed priming. Horticultural Reviews, v.16, p.109139, 1994.

PASSAM, H.C.; KARAVITES, P.I.; PAPANDREOU, A.A.; THANOS, C.A.; GEORGHIOU, K. Osmoconditioning of seeds in relation to growth and fruit yield of aubergine, pepper, cucumber and melon in unheated greenhouse cultivation. Scientia Horticulturae, v.38, p.217-216, 1989.

RAO, S.C.; AKERS, S.W.; AHRING, R.M. Priming brassica seed to improve emergence under different temperatures and soil moisture conditions. Crop Science, v.27, p.1050-1053, 1987.

ROVIERI JOSÉ, S.C.B. Condicionamento osmótico de sementes de pimentão: efeito na germinação, vigor e atividade enzimática. 1999. 107 f. (Tese mestrado) - UFLA, Lavras.

RUSH, C.M. Comparison of seed priming techniques with regard to seedling emergence and Pythium damping-off in sugar beet. Phytopathology, v.81, n.8, p.878-882, 1991.

SACHS, M. Priming of watermelon seeds for lowtemperature germination. Journal of the American Society for Horticultural Sciences, v.102, n.2, p.175-178, 1977.

SAMPAIO, N.V; SAMPAIO, T.G. Viabilidade, vigor e armazenamento de sementes de cenoura (Daucus carota L.) submetidas ao pré-condicionamento osmótico. Revista Ciência Rural, Santa Maria, v.3, n.2, p.38-45, 1998.

SZAFIROWSKA, A.; KHAN, A.A.; PECK, N.H. Osmoconditioning of carrot seeds to improve seedling establishment and yield in cold soil. Agronomy Journal, v.73, p.845-848, 1981.

TAYLOR, A.G.; HADAR, Y.; NORTON, J.M.; KHAN, A.A.; HARMAN, G.E. Influence of presowing seed treatments of table beets on the susceptibility to damping-off caused by Pythium. Journal of the American Society for Horticultural Science, v.110, n.4, p.516-519, 1985.

TRIGO, M.F.O.O.; TRIGO, L.F.N. Efeito do condicionamento osmótico na germinação e no vigor de sementes de berinjela (Solanum melongena L.). Revista Brasileira de Sementes, v.21, n.1, p.107113. 1999.

WELBAUM, G.E.; BRADFORD, K.J. Water relations of seed development and germination in muskmelon (Cucumis melo L.). VI. Influence of priming on germination responses to temperature and water potential during seed development. Journal of Experimental Botany, v.42, p.393-399, 1991.

ZHENG, G.H.; WILEN, R.W.; SLINKARD, A.E.; GUSTA, L.V. Enhancement of canola seed germination and seedling emergence at low temperature by priming. Crop Science, v.34, p.1589-1593, 1994. 